\title{
КОНСТРУИРОВАНИЕ ЗАДАНИЙ ПО ЕСТЕСТВЕННОНАУЧНОЙ ГРАМОТНОСТИ ПРИ ОБУЧЕНИИ ШКОЛЬНИКОВ БЕЗОПАСНОМУ ПОВЕДЕНИЮ
}

\section{DESIGN OF TASKS ON NATURAL SCIENCE LITERACY WHEN TEACHING SCHOOLCHILDREN SAFE BEHAVIOR}

\section{A. Volovodenko}

Summary: The article presents the results of experimental search work on the design of tasks acting as a tool for monitoring natural science literacy, in the process of forming safe behavior of schoolchildren. The theory of safe behavior is supplemented by a generalization of skills that reveal the competencies of natural science literacy and the content of tasks that exhibit these skills. Examples of tasks developed based on the requirements of PISA studies for students of the main general education school are given.

Keywords: natural science literacy, schoolchildren, skills and competencies, tasks, safe behavior.

\author{
Воловоденко Анжела Сергеевна \\ К.п.н., дочент, Омский государственный \\ педагогический университет \\ Volovodenko-angela@yandex.ru
}

Аннотация: В статье представлены результаты опытно-поисковой работы по конструированию заданий, выступающих инструментом мониторинга естественнонаучной грамотности, в процессе формирования безопасного поведения школьников. Теория безопасного поведения дополнена обобщением умений, раскрывающих компетенции естественнонаучной грамотности, и содержанием заданий, проявляющих эти умения. Приведены примеры заданий, разработанных с опорой на требования исследований PISA, для 0бучающихся основной общеобразовательной школы.

Ключевые слова: естественнонаучная грамотность, школьники, умения и компетенции, задания, безопасное поведение.
B опрос формирования функциональной грамотности школьников, в том числе естественнонаучной грамотности, все чаще заслуживает внимания авторов педагогических исследований. Промежуточные результаты мониторинга (в 5 - 9-х классах), реализуемого институтом стратегии развития образования РАО (на период 2019 - 2024 годы), позволяют актуализировать ряд проблем по данному направлению. В частности, речь идет о подходах к разработке заданий, обеспечивающих формирование и диагностику разных видов функциональной грамотности [1, с.28-29].

Останавливаясь на естественнонаучной грамотноcmu (EHГ), будем учитывать, что в обобщенном виде она трактуется как компетенции решения естественнонаучных проблем, что предполагает общее целеполагание в естественных науках, проблемность обучения, интегрированный характер в области изучения [2, с.37]. Также нельзя не согласиться с тем, что ЕНГ многокомпонентная и включает наряду с компетенциями когнитивный блок (знания об окружающем мире и естественных науках), контекстный блок (жизненный характер ситуаций), мотивационно-ценностный блок (совокупность характеристик, обусловливающих определенный тип поведения) [3, c.103].

Вышесказанное во многом совпадает с аспектами безопасного поведения школьников: воспитание лич- ностных характеристик (мотивы и ценности безопасного и здорового образа жизни), теоретическая подготовка (знания об организме и окружающей среде), виды деятельности (умения и навыки, реализующие элементы безопасности и здоровьесбережения на практике) $[4$, с.8]. В контексте такого понимания в результатах образовательных достижений обучающихся в рамках разных предметных областей (ФГОС ООО) прослеживается проявление такого типа поведения. Поэтому, рассматривая ЕНГ в разрезе процесса формирования безопасного поведения, подчеркнем значимость метапредметного характера ЕНГ, не сводя ее к интегрированию отдельных предметных результатов.

Задачей нашего исследования является конструирование заданий, проверяющих естественнонаучную грамотность, в условиях формирования безопасного поведения школьников. При выполнении задачи были проанализированы умения, составляющие компетенции ЕНГ [4, с.83 - 85], формы заданий [5, с.180 - 183], которые уже описаны учеными.

\section{Компетенция: научное объяснение явлений}

1. Умения ЕНГ: применение естественнонаучных знаний для объяснения явления.

Умения безопасного поведения: узнавание изобра- 
женного объекта или явления как источника опасности, выбор опасного/безопасного объекта или явления по критериям; определение опасности по ее описанию или действиям очевидцев и пострадавших; установление общих и отличительных признаков видов опасных и чрезвычайных ситуаций.

\section{Пример задания:}

Ситуачия: Жителям острова Мальта пришлось однажды увидеть, как разгневалась природа. По словам очевидчев, мощный вихрь зародился над поверхностью Средиземного моря. Потопив и поломав в бухте большую часть судов, он направился к острову. Выйдя на сушу, вихрь с легкостью поднимал в воздух жилые постройки, часть населенных пунктов.

Bonрос: О каком стихийном бедствии рассказывают мальтийцы? Запишите в бланк название чрезвычайной ситуации и объясните свой ответ.

2. Умения ЕНГ: распознавание, использование и создание объяснительной модели, представления.

Умения безопасного поведения: выделение в изображении или описании опасного/безопасного объекта или явления составляющих частей (и, наоборот, создание из отдельных частей целого); выбор запретных/правильных действий в поведении, представленном для конкретной ситуации.

\section{Пример задания:}

Cитуация: На столе несколько «витаминных» салатов. В первой тарелке - мелко натертая морковь, во второй - нарезанный красный переи, в третьей - нашинкованная капуста, в четвертой - нарезанная тыква.

Bonpoc: В каком случае можно посоветовать не заправлять овощи маслом или майонезом? Запишите в бланк номер выбранной тарелки и объясните свои рекомендации.

3. Умения ЕНГ: прогнозирование, научное обоснование прогнозов о протекании процесса или явления

Умения безопасного поведения: выявление закономерности в ряду объектов или явлений, представляющих угрозу; установление связи между событиями в предложенной ситуации по принципу «причина - следствие» в условиях прогнозирования опасности и ее последствий.

\section{Пример задания:}

Ситуачия: Во время выполнения лабораторной ра- боты в кабинете химии часть раствора щелочи из пробирки попала школьнику на руку. Мальчик жалуется на жгучую боль, на коже появилось покраснение.

Bonрос: Что нужно сделать в первую очередь, чтобы оказать помощь в этой ситуации? Выберите одно верное действие:

a) сопроводить мальчика к школьному фельдшеру;

б) предложить мальчику обезболивающее средство;

в) промыть обожженную руку под струей холодной воды

г) наложить на место ожога стерильную салфетку.

4. Умения ЕНГ: объяснение принципа действия технического устройства или технологии.

Умения безопасного поведения: выделение существенных признаков в изображении или описании объекта или явления, а также определение признака, по которому составлен алгоритм действий в условиях защиты, оказания первой помощи; установление соответствия между несколькими действиями в модели опасного/безопасного поведения.

Пример задания:

Ситуачия: Во время транспортной аварии у двух пассажиров зафиксированы похожие травмы: у женщины - перелом плечевой кости, а у мужчины - перелом локтевой кости. Для оказания помощи на месте происшествия, спасатели открыли два комплекта шин: в комплекте №1 две планки длиной 45 см, а в комплекте №2 - одна планка длиной 60 см, а вторая планка - 75 см.

Bonрос: Какой из двух комплектов шин специалисты будут накладывать на поврежденную руку женщине, а какой - мужчине? Запишите в бланк соответствие по форме «женшина/мужчина - № комплекта шин» и объясните свой выбор.

\section{Компетеншия: понимание особенностей естественнонаучного исслеАования}

5. Умения ЕНГ: распознавание и формулирование цели естественнонаучного исследования.

Умения безопасного поведения: построение серии установок на здоровый и безопасный образ жизни на основе анализа представленных признаков; определение вида первой помощи, мер защиты по совокупности средств или действий, которые изображены или описаны в ситуации.

Пример задания:

Ситуация: Зимние каникулы ребята проводят на бе- 
регу замерзшего водоема. Один из сверстников выполнил следующие действия: определил ивет льда, его прозрачность; измерил, много ли выпавшего снега на поверхности; определил, где растут водные растения и какова скорость течения.

Bonpoc: Какую чель преследовал мальчик, совершая такие действия? Запишите в бланк ответ одним предложением.

6. Умения ЕНГ: нахождение или оценивание способа научного исследования данного вопроса.

Умения безопасного поведения: нахождение объектов или явлений здорового и безопасного образа жизни из предложенного перечня по указанным или выбранным критериям, распределение их на группы; выделение верных/неверных утверждений, описывающих правила поведения в повседневной жизни, восполнение недостающих действий в алгоритмах для ситуаций опасных и чрезвычайных.

\section{Пример задания:}

Cитуация: В супермаркете хозяйка делает покупки: в овощном отделе - лук, сельдерей, помидоры; в мясном отделе - копченая колбаса, филе курицы; из молочных продуктов - масло сливочное, майонез; из кондитерских изделий - шоколадные батончики.

Bопрос: Какие продукты лучше исключить из этой продовольственной корзины? Запишите в бланк обнаруженные вредные продукты и объясните опасность, которую таит каждый из них.

7. Умения ЕНГ: нахождение объяснительных гипотез и способов их проверки.

Умения безопасного поведения: сравнение объектов или явлений как средств, ориентированных на сохранение жизни и здоровья, установление лишнего из приведенного перечня; анализ ситуации, установление соответствий и оценка действий, связанных с навыками безопасного поведения.

Пример задания:

Cuтуация: В результате падения у велосипедиста поврежден кровеносный сосуд на ноге, других травм нет. Свидетели происшествия пришли на помощь: нога пострадавшего была согнута в коленном суставе и зафиксирована в таком положении тугим бинтованием.

Bonpoc: Предположите, какой кровеносный сосуд был поврежден (артерия голени, вена голени, артерия бедра, вена бедра)? Какая дополнительная информация о трав- ме позволит проверить сделанное предположение? В бланк запишите один выбранный ответ и один вопрос (без указания элементов, которые есть в ответах!), уточняющий описание травмы.

8. Умения ЕНГ: описание и оценивание способов для обеспечения надежности данных и достоверности объяснений.

Умения безопасного поведения: выделение существенных признаков средств и мер защиты; ранжирование способов действий в порядке изменения исследуемого признака с направленностью на здоровый и безопасный образ жизни.

\section{Пример задания:}

Ситуация: Меню пятиклассника на 1 день недели выглядит следующим образом: завтрак - каша рисовая (200 ккал), винегрет из овощей (60 ккал), чай с сахаром (50 ккал); обед - овощной суп (45 ккал), мясные котлеты с картофелем (250 ккал), сок; ужин - блинчики с творогом (200 ккал), компот (60 ккал). Известно, что мальчик ведет активный образ жизни, увлекается футболом.

Bonpoc: Можно ли питание школьника однозначно оценить как правильное? Запишите в бланк принципы рационального питания, которые необходимо знать для достоверного ответа на этот вопрос.

\section{Компетеншия: интерпреташия $\Delta$ анных и использование научных $А$ оказательств А я получения выво $о в$}

9. Умения ЕНГ: анализ, интерпретация данных и формулирование выводов.

Умения безопасного поведения: анализ объектов или явлений, определяющих опасность/безопасность; установление причинно- следственных связей среди множества действий, формирующих поведение в данных обстоятельствах.

Пример задания:

Ситуация: Друзья купили билеты в одно купе поезда:у них два нижних места и два верхних (к заданию приложена схема купейного вагона).

Bonpoc: Какое место в данном купе наиболее опасное? Запишите в бланк номер опасного места и объясните свой выбор.

10. Умения ЕНГ: преобразование одной формы представления данных в другую.

Умения безопасного поведения: построение рече- 
вого высказывания по схемам, отражающим опасные/ безопасные объекты или явления, виды повседневных, опасных или чрезвычайных ситуаций, соответствующие алгоритмы действий (или, наоборот, построение схемы).

Пример задания:

Ситуачия: На химическом заводе произошла утечка отравляющего вещества. Получив сообщение об аварии, люди покидают опасный район (к заданию приложено изображение эвакуации населения).

Bonрос: Какую техногенную ситуацию иллюстрирует схема эвакуации? Запишите в бланк название химически опасного вещества и объясните действия населения.

11. Умения ЕНГ: распознавание допущения, доказательства и рассуждения в научных текстах.

Умения безопасного поведения: построение логической цепочки, связывающей объекты или явления, способы действий в модели опасного/безопасного поведения.

\section{Пример задания:}

Ситуачия: Миша готовит доклад о травматизме. Вот фрагмент его сообщения: «Известно, что перелом это повреждение, связанное с нарушением целостности кости. Одним из характерных признаков этой травмы может быть звук, возникающий при трении костных обломков. Оказывая помощь, пострадавшему накладывают шину».

Bопрос: Опираясь на аргументы, приведенные в тексте, объясните, почему средством первой помощи при переломах является шина?

12. Умения ЕНГ: оценивание с научной точки зрения аргументов и доказательств из различных источников.

Умения безопасного поведения: выделение суще- ственной информации в описании средств и мер защиты, способов действий в обеспечении безопасности людей и окружающей среды; выбор верных/неверных утверждений в соответствии с определяющими признаками опасных/безопасных объектов или явлений.

\section{Пример задания:}

Cитуачия: В выпуске телевизионной программы идет репортаж об истории инфекционных заболеваний. Фрагмент исторической справки: «Дизентерия - острая кишечная инфекция, в 90\% случаев встречается у детей. В народе за ней закрепилось название «болезнь грязных рук»»).

Bonpoc: Можно ли согласиться с народным названием этой инфекции? Запишите в бланк краткое объяснение.

Отметим, что каждый пример является элементом, включенным в систему заданий. В конкретном случае представлены задания для обучающихся разных возрастных групп, они не объединены тематически.

Обобщая изложенный материал, можно сделать следующие выводы:

- Обучение школьников безопасному поведению рассматривается как процесс, сопряженный с формированием у них естественнонаучной грамотности.

- На основе анализа компонентов, составляющих компетенции естественнонаучной грамотности, уточнены умения безопасного поведения школьников, что позволило в дальнейшем конструировать задания, раскрывающие компетенции ЕНГ.

- Содержание заданий, разработано в соответствии с требованиями ФГОС для общеобразовательной школы с ориентацией обучающихся на личную и социальную безопасность; в этой связи можно рекомендовать их применение в педагогической практике, например, для предметной области «Естественные науки», учебных предметов «Экология», «Основы безопасность жизнедеятельноСти».

\section{ЛИТЕРАТУРА}

1. Басюк В.С., Ковалева Г.С. Инновационный проект Министерства просвещения. Мониторинг формирования функциональной грамотности: основные направления и первые результаты // Отечественная и зарубежная педагогика. М.: ФГБНУ «Институт стратегии развития образования РА0». 2019. Т.1, № 4 (61). C. $13-33$.

2. Машиньян А.А., Кочергина Н.В. Демонстрационно-информационные комплексы школьного курса физики как средства формирования естественнонаучной грамотности // Перспективы Науки и Образования. Воронеж: 000 «Экологическая помощь». 2016. № 5 (23). С. 36 - 45.

3. Шимко Е.А. Условия формирования и диагностики отдельных компонентов естественнонаучной грамотности // Школьные технологии. М.: АНО ИД «Народное образование». 2019. № 2. С. $102-112$.

4. Марчук Н.Ю., Пестова И.В., Дильмиева Т.Р. Методические материалы по вопросам формирования навыков безопасного поведения у детей и подростков. Екатеринбург: ГБоу СО ЦППРиК «Ладо», 2014. 52 с. 
5. Пентин А.Ю., Никифоров Г.Г., Никишова Е.А. Основные подходы к оценке естественнонаучной грамотности // Отечественная и зарубежная педагогика. М.: ФГБНУ «Институт стратегии развития образования РА0». 2019. Т.1, № 4 (61). С. 80 - 97.

6. Пентин А.Ю., Никифоров Г.Г., Никишова Е.А. Формы использования заданий по оцениванию и формированию естественнонаучной грамотности в учебном процессе // Отечественная и зарубежная педагогика. М.: ФГБНУ «Институт стратегии развития образования РАО». 2019. Т.1, № 4 (61). С. 177 - 195.

\footnotetext{
๑ Воловоденко Анжела Сергеевна (Volovodenko-angela@yandex.ru).

Журнал «Современная наука: актуальные проблемы теории и практики»
}

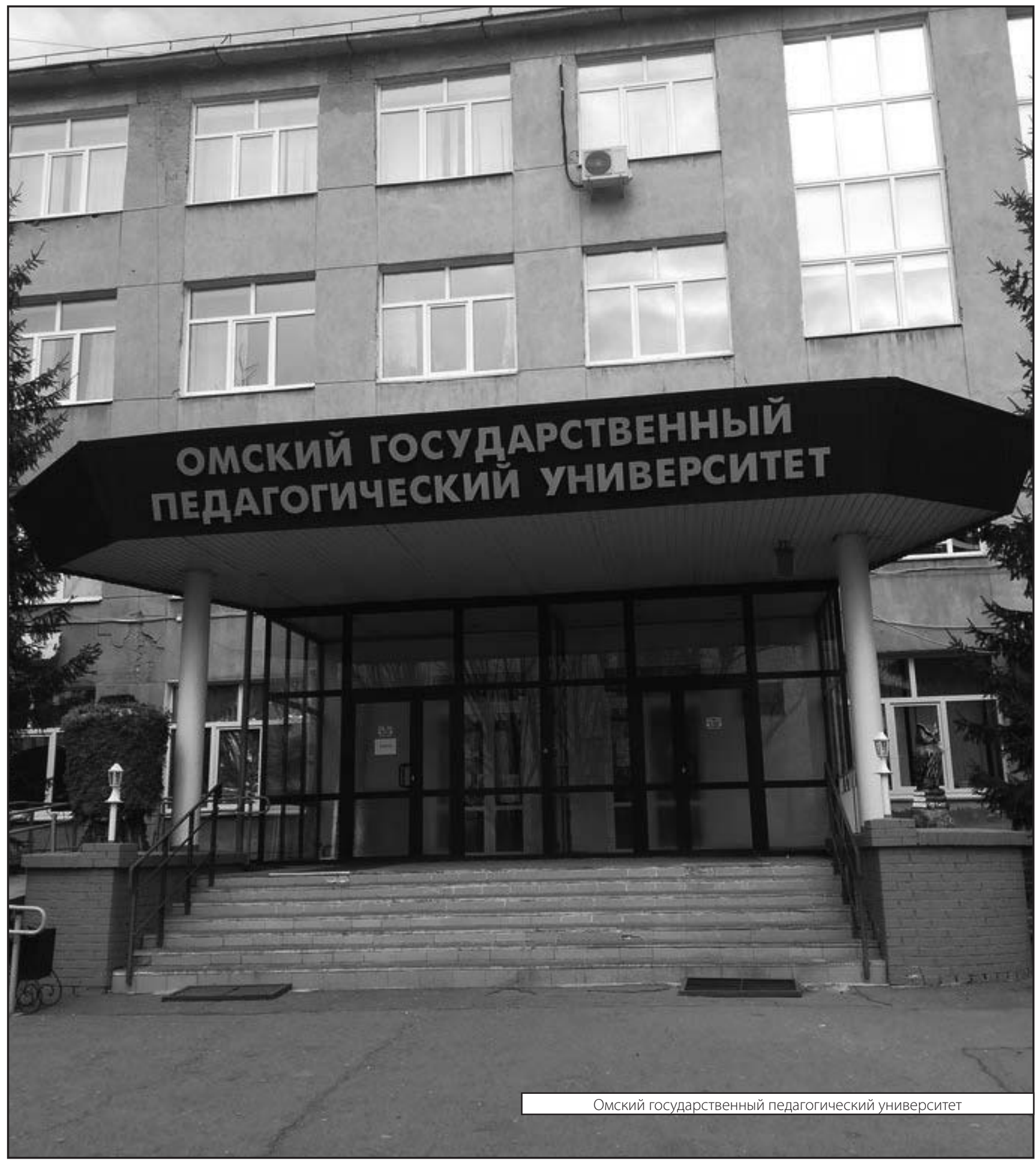

